\title{
Development of novel supported iridium nanocatalysts for special catalytic beds
}

\author{
Zahra Amirsardari $^{1} \cdot$ Akram Dourani $^{1} \cdot$ Mohamad Ali Amirifar $^{1} \cdot$ Nooredin Ghadiri Massoom $^{1} \cdot$ Rahim Ehsani $^{1}$
}

Received: 1 October 2019 / Accepted: 15 December 2019 / Published online: 26 December 2019

(c) The Author(s) 2019

\begin{abstract}
In the present paper, an experimental study of the catalytic decomposition of hydrous hydrazine was investigated on the different structural forms of the catalyst. The synthesized iridium catalysts have been usually used directly and have not been evaluated in the laboratory reactor. This study includes the preparation of iridium-based catalysts supported on spherical (alumina), honeycomb monoliths (cordierite) and foams (alumina) for the evaluation of catalytic activity in the laboratory reactor. The characterizations of these catalysts were evaluated by the TGA, FESEM and BET analysis. The result of the catalytic characterization of monolithic support was shown a homogeneous distribution of active metal without any problem of sintering (average size $25 \mathrm{~nm}$ ) on the support surface. While the surface of the spherical and foam supports were shown non-uniform distribution of nanoparticles on the support skeleton (average size $55 \mathrm{~nm}$ ). The monolithic catalyst exhibits higher decomposition rate and $\mathrm{H}_{2}$ selectivity than other supports due to uniform in shape and particle size distribution.
\end{abstract}

Zahra Amirsardari

Z.amirsardari@isrc.ac.ir

1 Space Transportation Research Institute, Iranian Space Research Center, Tehran, Iran 


\section{Graphic abstract}

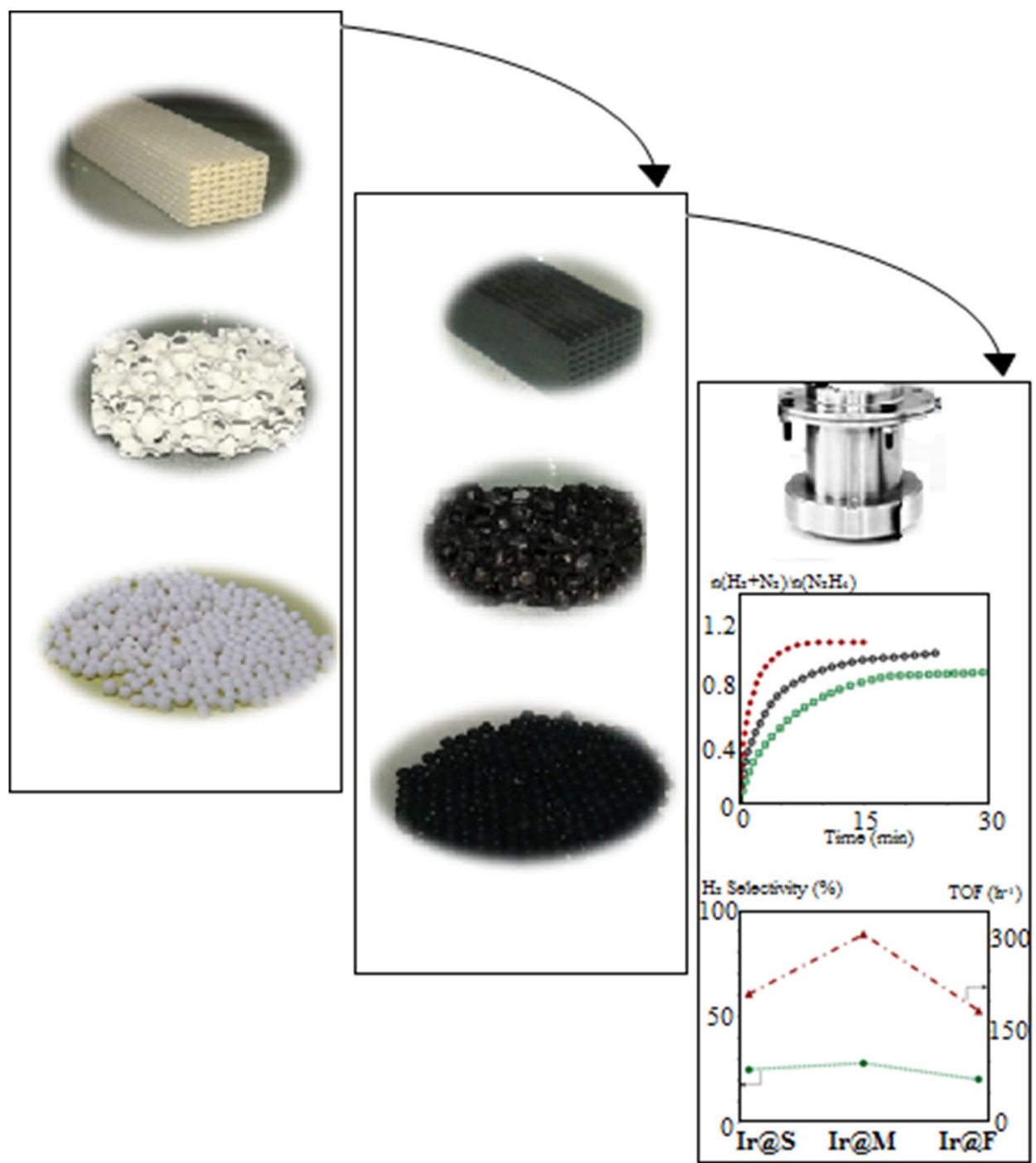

Keywords Iridium nanoparticles $\cdot$ Support shape $\cdot$ Catalyst activity $\cdot$ Laboratory reactor

\section{Introduction}

The catalyst efficiency relates to the active phase and carrier effects and also the operating properties [1]. Depending on the support type of catalyst, the reaction rate of the catalyst differs, although it does not directly participate in the catalytic reaction [2-6]. In general, an ideal support should have high thermomechanical strength, and high specific surface area in harsh operation [7]. Although the catalyst support plays a key role in enhancing the overall rate of catalytic decomposition, very few comparative studies have been carried out on the efficiency of different catalyst supports in hydrazine decomposition. The reason is that most researchers have done their studies using one form of support rather than using different carriers for a desired reaction [8-11]. Perhaps, because the commercial catalyst (iridium on gamma-alumina) for hydrazine decomposition has a spherical form [12-14], less has been paid to various forms of catalyst support in the present papers, but in the species such as hydrogen peroxides, there are some reports about the influence of the shape of catalyst support on the decomposition rate [15-17].

Some researchers were showed the grain size has a strong influence on the properties, the surface increases when the size of the grains decreases which leads to a higher activity $[18,19]$. In other work, An and co-workers showed in hydrogen peroxide bed, the performance was better when using alumina pellets than when using 
monolith support because of higher bed pressure and temperature [20]. Hence, an appropriate form and structure of the supported iridium catalysts based on the catalytic decomposition of hydrazine or hydrazine borane can be a good alternative to existing catalysts [21, 22]. The direct effect of surface area and structure on the catalytic activity of iridium is quite evident. However, no papers as far as we known have reported the comparative properties of the iridium nanoparticles by introducing iridium ions on the surface of different supports in the area of catalytic decomposition of hydrazine monohydrate.

Iridium catalyst alone is intended for hydrazine decomposition and the addition of nickel to it is not appropriate. Nickel or cobalt catalyst along with iridium is suitable for the hydrogen storage materials. Few researches have been focused on the iridium catalyst for hydrazine decomposition in special forms. One of the major challenges in high pressure is the destruction of supports under high operating temperatures and pressures [23, 24]; therefore, our studies are warranted to complete research about the use of these catalysts for hydrazine decomposition. Since an acceptable catalyst support is required for the purposeful and proper operation, synthetic catalyst optimization is needed.

A suitable decomposition iridium catalyst is reported, which carries on-spherical granules, honeycomb monoliths and foams. The characteristics of the synthesized catalytic were compared to each other in the selective hydrogenation and reaction rate of hydrazine decomposition. Notably, granular, foam, and monolith showed different activity during decomposition of hydrazine monohydrate, mainly because of the various distributions and availability of iridium nanoparticles. Different sizes of nanoparticles formed on different supports affect the rate of hydrazine degradation.

\section{Experimental}

The supports were dried at $100-120{ }^{\circ} \mathrm{C}$ in the muffle oven for $12 \mathrm{~h}$ to remove moisture. Then, an aqueous solution of dihydrogen hexachloroiridate(IV) hydrate $\left(\mathrm{H}_{2} \mathrm{IrCl}_{6} \cdot x \mathrm{H}_{2} \mathrm{O}\right.$, Sigma-Aldrich) precursor was ready at room temperature during the overnight.

First, to increase the internal surface area, the asreceived monolith (cordierite with 400 cells per square inch) and foam (alumina with 20 pore per inch) were washcoated into the $\alpha$-alumina, $\gamma$-alumina, and polyvinyl alcohol sol with equal weight, and suspended in water for $1 \mathrm{~h}$ with careful control of the temperature and viscosity. Up to three washcoat stages can be done to get a given porous washcoat support, and the washcoat layers were dried at $100{ }^{\circ} \mathrm{C}$ during $12 \mathrm{~h}$ and calcined at $700{ }^{\circ} \mathrm{C}$ for $4 \mathrm{~h}$.
The washcoat supports and $\gamma$-alumina spherical granules were loaded with iridium nanoparticles by wet impregnation using the $\mathrm{H}_{2} \mathrm{IrCl}_{6} \cdot x \mathrm{H}_{2} \mathrm{O}$ solution as the precursor for five times. The catalysts were dried at $80^{\circ} \mathrm{C}$ for $24 \mathrm{~h}$ and finally calcined at $400{ }^{\circ} \mathrm{C}$ for $3 \mathrm{~h}$. The iridium loadings were controlled at $20 \mathrm{wt} \%$ of support and denoted as Ir@S, Ir@M, and Ir@F for corresponding catalysts with spherical granular, monolith, and foam supports, respectively. The iridium catalysts were used for decomposition of hydrazine monohydrate $\left(\mathrm{N}_{2} \mathrm{H}_{4} \cdot \mathrm{H}_{2} \mathrm{O}\right.$, Merck) in laboratory reactor.

The Ir nanoparticle microstructures are evaluated by field emission scanning electron microscopy (FESEM, MIRA3 Tescan) observation. The catalyst surface areas were examined with Brunauer-Emmet-Teller (BET, BELSORP-Mini, MicrotracBel Corp.) method. X-ray Diffraction (XRD) patterns were obtained in a PANalytical X'Pert diffractometer with a Co Ka radiation. Thermogravimetric treatments (TGA, Linseys, STA 1600) were studied at $25-1000{ }^{\circ} \mathrm{C}$ with the rate of $10{ }^{\circ} \mathrm{C} \mathrm{min}^{-1}$. The self-designed laboratory stainless steel reactor was applied for the decomposition of hydrazine monohydrate at $25^{\circ} \mathrm{C} .10 \mathrm{ml}$ of hydrazine monohydrate was added on $0.1 \mathrm{~g}$ of iridium catalyst. The generated gases was passed in $1 \mathrm{M} \mathrm{HCl}$ trap to absorb ammonia $\left(\mathrm{NH}_{3}\right)$ and measured through water displacement method. The number of hydrogen and nitrogen moles $(\lambda)$ calculated via the following equation:

$\lambda=\frac{n\left(\mathrm{~N}_{2}\right)+n\left(\mathrm{H}_{2}\right)}{n\left(\mathrm{~N}_{2} \mathrm{H}_{4}\right)}$.

The hydrogen selectivity $(X)$ was calculated from Eq. (1) with Eq. (2):

$X=\frac{3 \lambda-1}{8}\left[\lambda=\frac{n\left(\mathrm{~N}_{2}\right)+n\left(\mathrm{H}_{2}\right)}{n\left(\mathrm{~N}_{2} \mathrm{H}_{4}\right)}.\right]$

TOF or the reaction rate $\left(\mathrm{h}^{-1}\right)$ in $80 \%$ conversion of $\mathrm{N}_{2} \mathrm{H}_{4} \cdot \mathrm{H}_{2} \mathrm{O}$ was obtained as follows:

$\mathrm{TOF}=\frac{P V}{3 n_{\text {metal }} R T t}$,

where the universal gas constant is $R$, the reaction temperature is $T$, the atmospheric pressure is $P$, the mole number of iridium is $n_{\mathrm{Ir}}$, the volume of $\mathrm{H}_{2}$ and $\mathrm{N}_{2}$ is $\mathrm{V}$, and the reaction time is $t$.

\section{Results and discussion}

The BET surface area, pore volume, and average pore size after iridium coating in all three catalysts are summarized in Table 1 . It has been carefully selected a similar surface 
level of the supports. Two samples prepared by washcoating method, and spherical granule exhibit similar surface area (see Table 1). The BET properties between three supports were almost similar, suggested that the differences in the catalytic reactivity could arise from the tendency according to support types to hydrazine decomposition efficiency.

Figure 1 shows the XRD profiles of the catalyst as function of support shapes after calcination in $400{ }^{\circ} \mathrm{C}$. The locations of the iridium oxide and $\gamma$-alumina peaks for all three catalysts are within the specified range in the XRD patterns. In three patterns, the prominent peaks of $\mathrm{IrO}_{2}$ shown at $2 \theta \sim 27^{\circ}, 34^{\circ}$, and $54^{\circ}$, with the significant peaks of $\gamma-\mathrm{Al}_{2} \mathrm{O}_{3}$ at $2 \theta \sim 45^{\circ}$ and $65^{\circ}$. The peak at $2 \theta \sim 22^{\circ}$ indicates the presence of silica at the catalyst support in cordierite and foam. The mean iridium particle sizes determined using the Scherrer equation were $10 \mathrm{~nm}(\operatorname{Ir} @ S), 9 \mathrm{~nm}(\operatorname{Ir} @ M)$, and $18 \mathrm{~nm}$ (Ir@F). It seemed that smaller particle size was desirable for high activity in hydrazine monohydrate decomposition.

Figure 2 shows the weight loss profiles of iridium catalysts on different supports in TGA experiment between 25 and $1000{ }^{\circ} \mathrm{C}$. It is apparent from the TGA curves that no weight losses in monolithic catalyst were observed. Therefore, no harsh oxidation in the support is expected during the process of catalytic decomposition. Iridium on spherical granule and the foam catalysts exhibit a decrease at around $300{ }^{\circ} \mathrm{C}$. After this step there is a low mass decrease up to $1000{ }^{\circ} \mathrm{C}$ that can be arisen from slow decomposition of organic material in both catalysts. The total mass loss of Ir@S and Ir@F catalysts reaches 10\% and 6.5\% at $1000{ }^{\circ} \mathrm{C}$, respectively. These results show greater thermal stability of the monolithic catalyst than the spherical granules and foam catalysts.

FESEM pictures of the iridium catalysts are depicted in Fig. 3. These inspections show that the iridium nanoparticles almost cover all surfaces of the three types of catalyst supports (Fig. 3a-c), but some large agglomerations, or the bare surfaces of support are also observed in the Ir@S and Ir@F samples (Fig. 3a, c). Spherical granules produce accumulation of particles on the support surface and apparently reduce the smoothly surface. However, iridium nanoparticles

Table 1 BET properties of catalysts with different supports

\begin{tabular}{llll}
\hline Composition & $S_{\mathrm{BET}}\left(\mathrm{m}^{2} \mathrm{~g}^{-1}\right)$ & $\begin{array}{l}\text { Pore volume } \\
\left(\mathrm{cm}^{3} / \mathrm{g}\right)\end{array}$ & $\begin{array}{l}\text { Pore } \\
\text { diameter } \\
(\mathrm{nm})\end{array}$ \\
\hline Spherical granule & 40 & 0.07 & 20 \\
Monolith & 43 & 0.05 & 13 \\
Foam & 42 & 0.06 & 13 \\
Ir@S & 15 & 0.06 & 17 \\
Ir@M & 19 & 0.04 & 9 \\
Ir@F & 29 & 0.04 & 6.5 \\
\hline
\end{tabular}

on the washcoat monolith surface tend to be distributed homogeneously. It indicates that supports can coat with iridium nanoparticles with different sizes and shapes. The overcast of washcoat layer on support may be one of the reasons strong interaction of nanoparticles with the surface of the monolith. Also, these observations indicate iridium nanocrystals with various morphologies. It is obvious that iridium is composed of round particles $(50-60 \mathrm{~nm})$ on

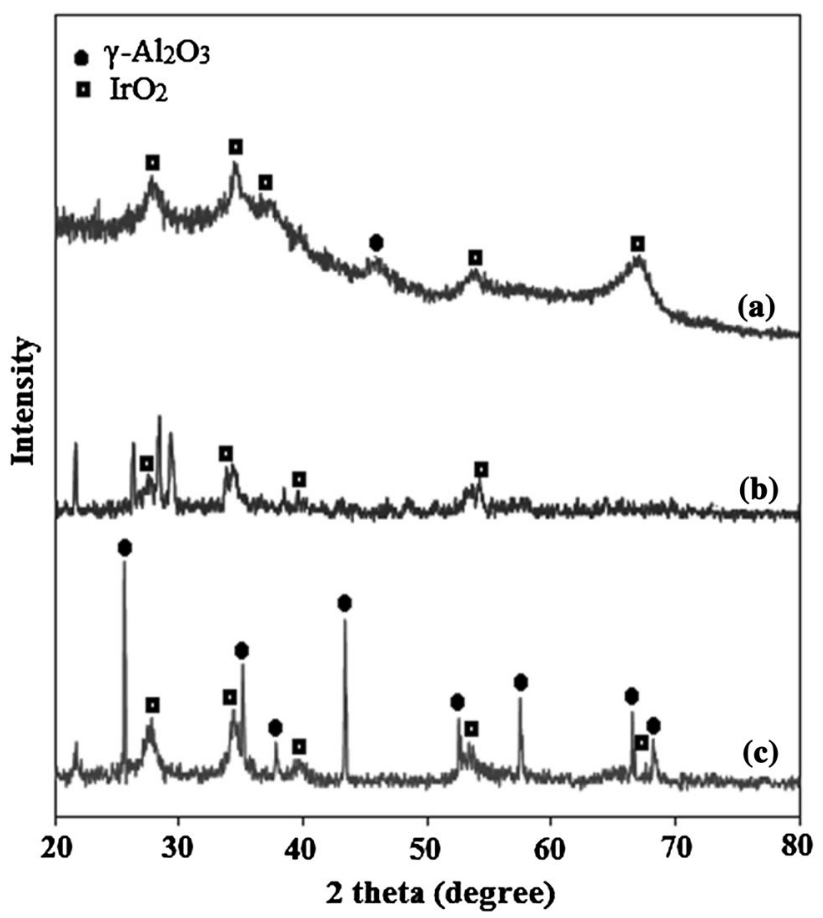

Fig. 1 XRD patterns of the catalyst with a spherical granule, $\mathbf{b}$ monolithic, and $\mathbf{c}$ foam supports

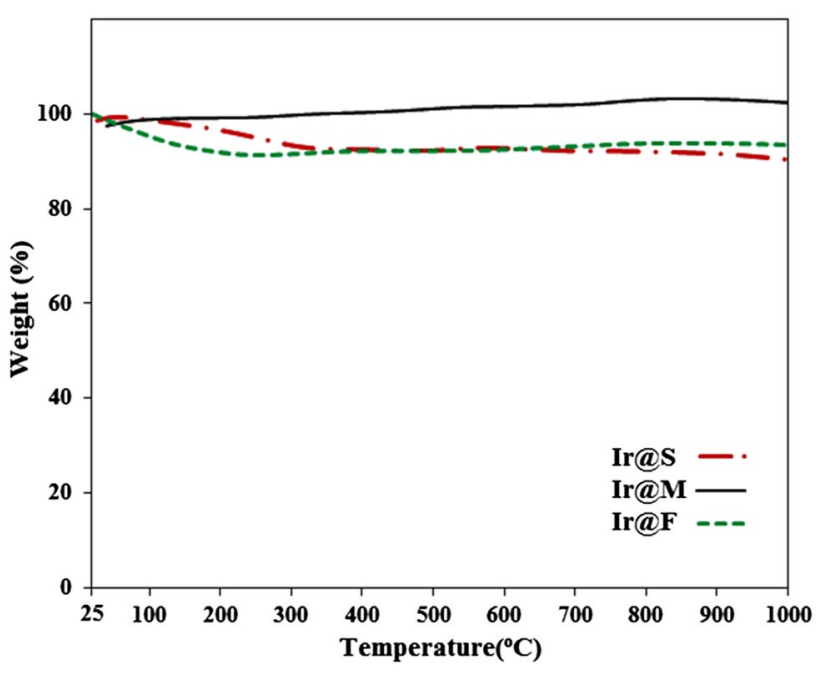

Fig. 2 TGA thermograms of catalysts 

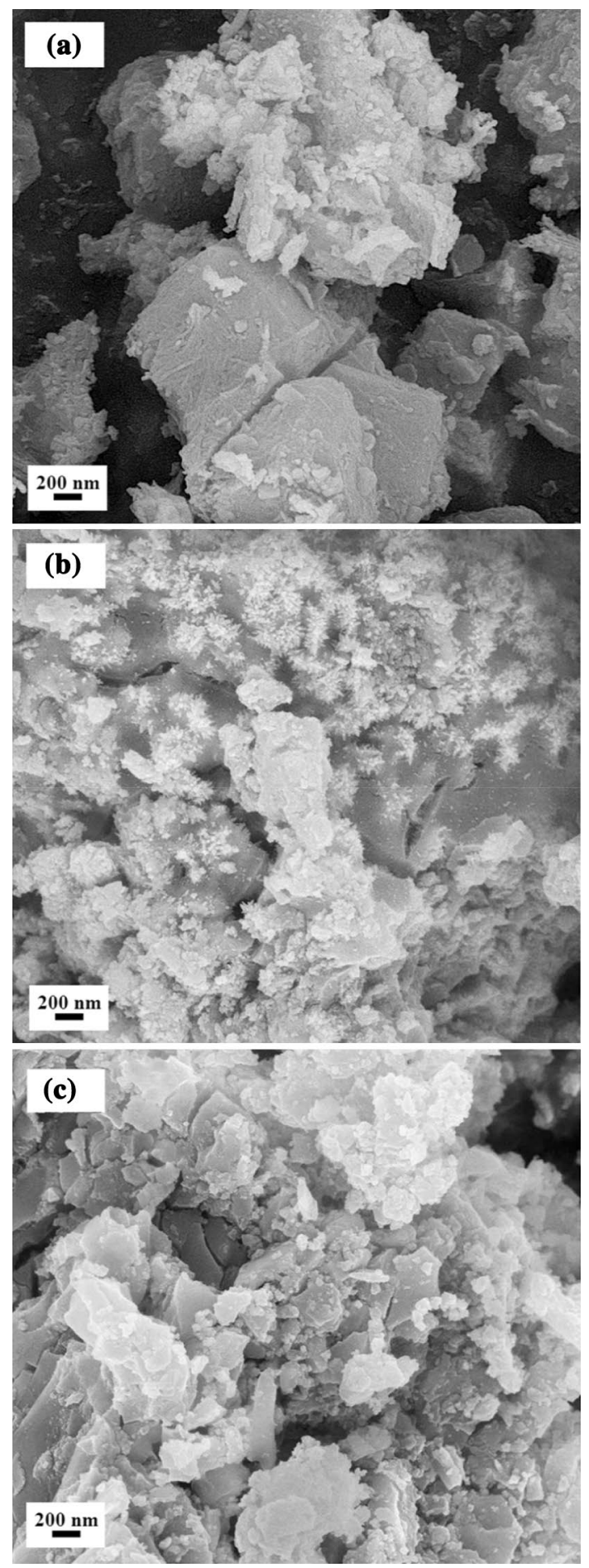

Fig. 3 FESEM pictures of a Ir@S, b Ir@M, and c Ir@ F catalysts

spherical granule and foam supports. On the other hand, the iridium nanoparticles on monolith show much better dispersion, which is mainly composed of needle-like nanoparticles with the size of $20-30 \mathrm{~nm}$.

Iridium-based catalytic systems have been known for long to be highly active and low hydrogen selectivity catalyst for hydrazine decomposition. In addition, iridium supported on different materials shows various activities and selectivity due to a more efficient distribution of nanoparticles. $\mathrm{N}_{2} \mathrm{H}_{4}$ can be adsorbed on the Ir surface via both $\mathrm{N}$ atoms. Hydrazine molecules on the iridium catalyst through exothermic reactions decompose into $\mathrm{NH}_{3}, \mathrm{H}_{2}$, and $\mathrm{N}_{2} . \mathrm{NH}_{3}$ and $\mathrm{N}_{2}$ are major gases when the temperature is low with slight $\mathrm{H}_{2}$ selectivity [25]. The reaction can be described in two steps [26]:

$3 \mathrm{~N}_{2} \mathrm{H}_{4} \rightarrow 4 \mathrm{NH}_{3}+\mathrm{N}_{2}$ (Exothermic),

$4 \mathrm{NH}_{3} \rightarrow 2 \mathrm{~N}_{2}+6 \mathrm{H}_{2}$ (Endothermic).

The $\mathrm{NH}_{3}$ dissociation with high activation temperature should be adjusted, since the working point moves away from the optimum at high dissociation, thus affecting bed performance. Therefore, decomposition becomes more important when the $\mathrm{NH}_{3}$ mass fraction begins to decrease. With the further decomposition of hydrazine and ammonia, the amount of product gases increases, and this high pressure of $\mathrm{H}_{2}$ prevents further ammonia decomposition [27].

Figure $4 a, b$ shows the time profiles of efficiency of three support, $\mathrm{H}_{2}$ selectivity and reaction rate of the catalysts under the similar conditions in the sealed reactor. The fact that the performance of the monolithic catalyst is better than other catalysts, because crystals on the monolith catalyst are smaller with the rapid diffusion transfer.

The Ir@M catalyst shows its activity by heat transfer and mass transfer in $15 \mathrm{~min}$, referring to a turnover frequency (TOF) of $310 \mathrm{~h}^{-1}$. For Ir@F, a low activity is shown with a TOF value of $185 \mathrm{~h}^{-1}$ in $30 \mathrm{~min}$. Ir@ $\mathrm{S}$ catalyst achieves a $\lambda$ value of 1 after $23.5 \mathrm{~min}$, with a lower TOF of $212 \mathrm{~h}^{-1}$. The significant drop in reaction rate and hydrogen selectivity of the Ir@F catalyst might be originated from the structural change of support. In this context, morphology with different shapes was developed on the textural properties of cordierite monolithic and foam substrates.

Notably, although Ir@S shows a decreased reaction rate compared to the Ir@M nanocatalyst, it offers an increase in hydrogen selectivity (25\%), with a yield close to monolithic catalyst (28\%). Comparatively, the $\mathrm{Ir} @ \mathrm{M}$ shows a more $\mathrm{H}_{2}$ selectivity owing to the production of hydrogen gas from ammonia. However, the reaction rate of hydrazine monohydrate decomposition seems very sensitive to the surface area of the catalysts. Indeed, the TOF increases when the nanoparticle size decreases in the surface of monolith support. The released gases from decomposition of hydrazine monohydrate is clearly a structure-sensitive reaction, being the active phase dispersion the most influencing parameter. The morphology and topologies of support surfaces effect on decomposition reaction and the changing sintering. In most studies, adding 

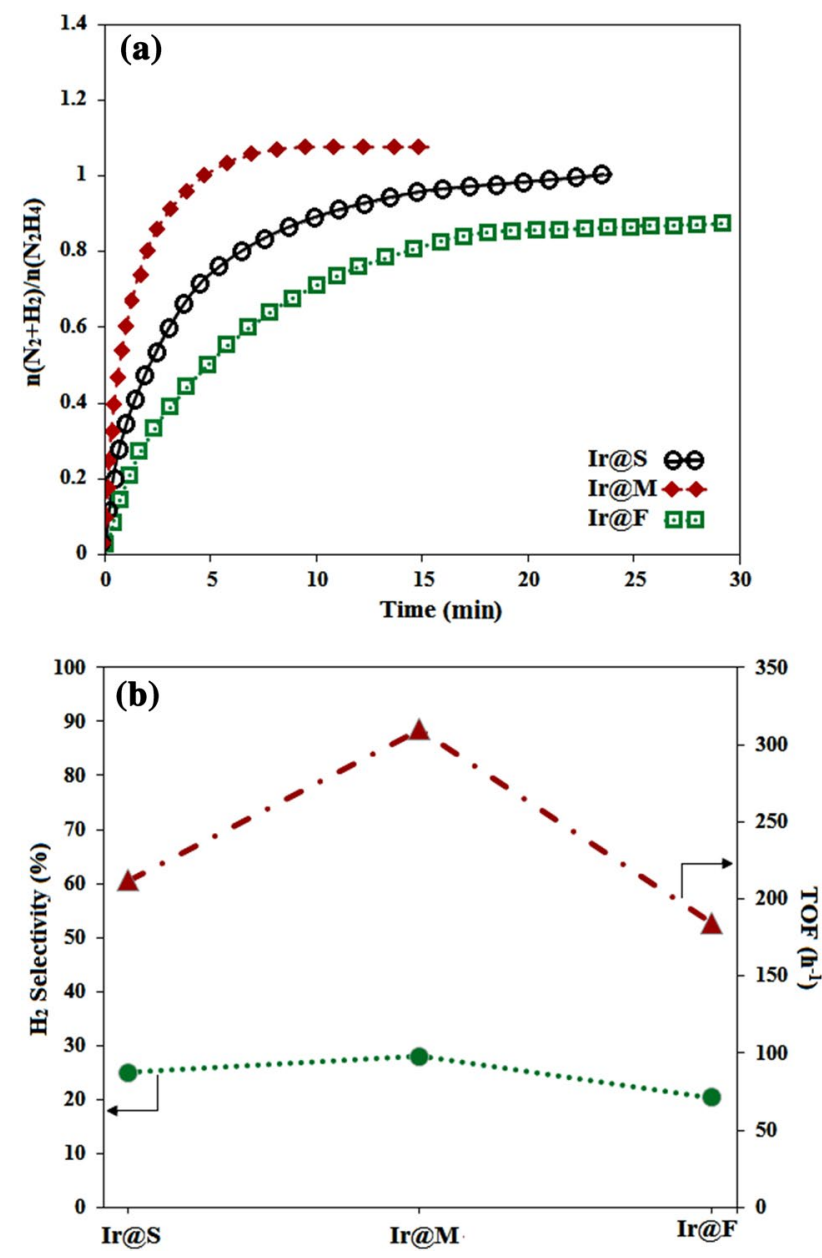

Fig. 4 a Hydrazine monohydrate decomposition curves, and $\mathbf{b}$ the comparison of $\mathrm{H}_{2}$ selectivity and reaction rate of the iridium catalysts on different supports

nickel to the iridium (or platinum) catalyst only improves the hydrogen selectivity properties, as shown in Table 2.

\section{Conclusions}

Making a high-strength catalyst can be a quick and easy way to access it for high operating temperatures and pressures. Hence, three types of catalyst with different support shapes (spherical granule, monolith, and pellets) were prepared, characterized and tested in the laboratory reactor for decomposition of hydrazine monohydrate. In all cases, total hydrogen selectivity is reached below $30 \%$, in spite that the $\mathrm{NH}_{3}$ conversion depends on both support and the active phase nature. TOF of the monolithic catalyst $\left(310 \mathrm{~h}^{-1}\right)$ was excellent, due to the following two reasons. First, fast and direct contact of the washcoat layer on all monolithic surfaces could be increased reaction rate; however, it was difficult to penetrate deeply inside the pores of the spherical granule
Table 2 Hydrazine monohydrate decomposition properties of different catalysts

\begin{tabular}{lllll}
\hline Catalyst & $T\left({ }^{\circ} \mathrm{C}\right)$ & $\mathrm{TOF}\left(\mathrm{h}^{-1}\right)$ & $\begin{array}{l}\mathrm{H}_{2} \\
\text { selectiv- } \\
\text { ity (\%) }\end{array}$ & References \\
\hline $\mathrm{CoIr}_{0.081} @ \mathrm{Al}_{2} \mathrm{O}_{3}$ & 25 & 27.7 & 100 & {$[28]$} \\
$\mathrm{NiIr}_{0.059} @ \mathrm{Al}_{2} \mathrm{O}_{3}$ & 70 & 84.3 & 97 & {$[8]$} \\
$\mathrm{Ni}_{85} \mathrm{Ir}_{15} @ \mathrm{MIL} 101$ & 25 & 24 & 100 & {$[29]$} \\
$\left(\mathrm{Ni}_{5} \mathrm{Pt}_{5}\right)_{1}\left(\mathrm{CeO}_{x}\right)_{0.5} / \mathrm{gra}-$ & 25 & 212 & 100 & {$[30]$} \\
$\mathrm{phene}$ & & & & \\
$\mathrm{Ni}_{60} \mathrm{Pt}_{40} / \mathrm{La}_{2} \mathrm{O}_{3}$ & 35 & 140 & 82 & {$[31]$} \\
$\mathrm{Ir} @ \mathrm{Monolith}_{\mathrm{Ir} @ \text { Alumina }}$ & 25 & 310 & 28 & This study \\
$\mathrm{Ir} @$ Foam & 25 & 212 & 25 & This study \\
\hline
\end{tabular}

by hydrazine monohydrate. Second, heat and mass transfer were effective in the monolithic catalyst, due to the channel structure. The time profile figure show that the monolithic is generally more desirable catalyst than that of spherical granule which is commonly used.

Open Access This article is licensed under a Creative Commons Attribution 4.0 International License, which permits use, sharing, adaptation, distribution and reproduction in any medium or format, as long as you give appropriate credit to the original author(s) and the source, provide a link to the Creative Commons licence, and indicate if changes were made. The images or other third party material in this article are included in the article's Creative Commons licence, unless indicated otherwise in a credit line to the material. If material is not included in the article's Creative Commons licence and your intended use is not permitted by statutory regulation or exceeds the permitted use, you will need to obtain permission directly from the copyright holder. To view a copy of this licence, visit http://creativecommons.org/licenses/by/4.0/.

\section{References}

1. Morales-Torres, S., Carrasco-Marín, F., Pérez-Cadenas, A., Maldonado-Hódar, F.: Coupling noble metals and carbon supports in the development of combustion catalysts for the abatement of BTX compounds in air streams. Catalysts. 5, 774-799 (2015)

2. Rahmani, S., Rezaei, M., Meshkani, F.: Preparation of highly active nickel catalysts supported on mesoporous nanocrystalline $\gamma-\mathrm{Al}_{2} \mathrm{O}_{3}$ for $\mathrm{CO}_{2}$ methanation. J. Ind. Eng. Chem. 20, 1346-1352 (2014)

3. Sen, B., Kuzu, S., Demir, E., Akocak, S., Sen, F.: Polymergraphene hybride decorated Pt nanoparticles as highly efficient and reusable catalyst for the dehydrogenation of dimethylamineborane at room temperature. Int. J. Hydrog. Energy 42, 2328423291 (2017)

4. Karatepe, Ö., Yıldız, Y., Pamuk, H., Eris, S., Dasdelen, Z., Sen, F.: Enhanced electrocatalytic activity and durability of highly monodisperse Pt@ PPy-PANI nanocomposites as a novel catalyst for the electro-oxidation of methanol. RSC Adv. 6, 50851-50857 (2016)

5. Eris, S., Daşdelen, Z., Yıldız, Y., Sen, F.: Nanostructured Polyaniline-rGO decorated platinum catalyst with enhanced activity 
and durability for Methanol oxidation. Int. J. Hydrog. Energy 43, 1337-1343 (2018)

6. Daşdelen, Z., Yıldız, Y., Eriş, S., Şen, F.: Enhanced electrocatalytic activity and durability of Pt nanoparticles decorated on GO-PVP hybride material for methanol oxidation reaction. Appl. Catal. B Environ. 219, 511-516 (2017)

7. Dolci, S., Dell'Amico, D.B., Pasini, A., Torre, L., Pace, G., Valentini, D.: Platinum catalysts development for $98 \%$ hydrogen peroxide decomposition in pulsed monopropellant thrusters. J. Propuls. Power. 31, 1204-1216 (2015)

8. He, L., Huang, Y., Liu, X.Y., Li, L., Wang, A., Wang, X., Mou, C.-Y., Zhang, T.: Structural and catalytic properties of supported $\mathrm{Ni}-\mathrm{Ir}$ alloy catalysts for $\mathrm{H}_{2}$ generation via hydrous hydrazine decomposition. Appl. Catal. B Environ. 147, 779-788 (2014)

9. Amirsardari, Z., Dourani, A., Amirifar, M.A., Massoom, N.G., Jahannama, M.R.: Controlled attachment of ultrafine iridium nanoparticles on mesoporous aluminosilicate granules with carbon nanotubes and acetyl acetone. Mater. Chem. Phys. 239, 122015 (2020)

10. Jain, P., Anila, K.A., Vinod, C.P.: Au based Ni and Co bimetallic core shell nanocatalysts for room temperature selective decomposition of hydrous hydrazine to hydrogen. ChemistrySelect. 4, 2734-2740 (2019)

11. Cheng, Y., Wu, X., Xu, H.: Catalytic decomposition of hydrous hydrazine for hydrogen production. Sustain. Energy Fuels. 3, 343-365 (2019)

12. Adami, A., Mortazavi, M., Nosratollahi, M., Taheri, M., Sajadi, J.: Multidisciplinary design optimization and analysis of hydrazine monopropellant propulsion system. Int. J. Aerosp. Eng. 2015, 9 (2015)

13. Cui, M.-L., Chen, Y.-S., Xie, Q.-F., Yang, D.-P., Han, M.-Y.: Synthesis, properties and applications of noble metal iridium nanomaterials. Coord. Chem. Rev. 387, 450-462 (2019)

14. Koopmans, R.-J., Nandyala, V.R., Pavesi, S., Batonneau, Y., Beauchet, R., Maleix, C., Schwentenwein, M., Spitzbart, M., Altun, A.A., Scharlemann, C.: Comparison of HTP catalyst performance for different internal monolith structures. Acta Astronaut. 164, 106-111 (2019)

15. Lim, H., An, S., Kwon, S., Rang, S.: Hydrogen peroxide gas generator with dual catalytic beds for nonpreheating startup. J. Propuls. Power. 23, 1147-1151 (2007)

16. Torre, L., Pasini, A., Romeo, L., Cervone, A., D’Agostino, L.: Performance of a monopropellant thruster prototype using advanced hydrogen peroxide catalytic beds. J. Propuls. Power. 25, 12911299 (2009)

17. Klegová, A., Inayat, A., Indyka, P., Gryboś, J., Sojka, Z., Pacultová, K., Schwieger, W., Volodarskaja, A., Kuśtrowski, P., Rokicińska, A.: Cobalt mixed oxides deposited on the SiC opencell foams for nitrous oxide decomposition. Appl. Catal. B Environ. 255, 117745 (2019)

18. Amirsardari, Z., Aghdam, R.M., Salavati-Niasari, M., Jahannama, M.R.: The effect of starting precursors on size and shape modification of $\mathrm{ZrB}_{2}$ ceramic nanoparticles. J. Nanosci. Nanotechnol. 15, 10017-10021 (2015)
19. Amirsardari, Z., Aghdam, R.M., Salavati-Niasari, M., Shakhesi, S.: Preparation and characterization of a novel heteronanostructure of zirconium diboride nanoparticle-coated multi-walled carbon nanotubes. RSC Adv. 4, 61409-61414 (2014)

20. An, S., Lee, J., Brahmi, R., Kappenstein, C., Kwon, S.: Comparison of catalyst support between monolith and pellet in hydrogen peroxide thrusters. J. Propuls. Power. 26, 439-445 (2010)

21. Chen, J., Lu, Z.-H., Yao, Q., Feng, G., Luo, Y.: Complete dehydrogenation of $\mathrm{N}_{2} \mathrm{H}_{4} \mathrm{BH}_{3}$ with NiM-Cr $\mathrm{O}_{3}(\mathrm{M}=\mathrm{Pt}, \mathrm{Rh}$, and Ir) hybrid nanoparticles. J. Mater. Chem. A. 6, 20746-20752 (2018)

22. Hong, X., Yao, Q., Huang, M., Du, H., Lu, Z.-H.: Bimetallic NiIr nanoparticles supported on lanthanum oxy-carbonate as highly efficient catalysts for hydrogen evolution from hydrazine borane and hydrazine. Inorg. Chem. Front. 6, 2271-2278 (2019)

23. Amirsardari, Z., Aghdam, R.M., Jahannama, M.R.: Role of surface thermal properties of $\mathrm{HfB}_{2}$ nanoparticles on heat flow in MWCNT/novolac composites. Bull. Mater. Sci. 41, 11 (2018)

24. Amirsardari, Z., Aghdam, R.M.: Comparison of weight-loss changes with different compositions of $\mathrm{ZrB}_{2}$ nanoparticles in carbon fabric-novolac composite at high temperature. Micro Nano Lett. 12, 589-594 (2017)

25. Singh, S.K., Zhang, X.-B., Xu, Q.: Room-temperature hydrogen generation from hydrous hydrazine for chemical hydrogen storage. J. Am. Chem. Soc. 131, 9894-9895 (2009)

26. Hwang, C.H., Lee, S.N., Baek, S.W., Han, C.Y., Kim, S.K., Yu, M.J.: Effects of catalyst bed failure on thermochemical phenomena for a hydrazine monopropellant thruster using $\mathrm{Ir} / \mathrm{Al}_{2} \mathrm{O}_{3}$ catalysts. Ind. Eng. Chem. Res. 51(15), 5382-5393 (2012)

27. Shankar, V., Ram, K.A., Bhaskaran, K.A.: Prediction of the concentration of hydrazine decomposition products along a granular catalytic bed. Acta Astronaut. 11, 287-299 (1984)

28. Firdous, N., Janjua, N.K., Qazi, I., Wattoo, M.H.S.: Optimal Co-Ir bimetallic catalysts supported on $\gamma-\mathrm{Al}_{2} \mathrm{O}_{3}$ for hydrogen generation from hydrous hydrazine. Int. J. Hydrog. Energy 41, 984-995 (2016)

29. Zhao, P., Cao, N., Su, J., Luo, W., Cheng, G.: NiIr nanoparticles immobilized on the pores of MIL-101 as highly efficient catalyst toward hydrogen generation from hydrous hydrazine. ACS Sustain. Chem. Eng. 3, 1086-1093 (2015)

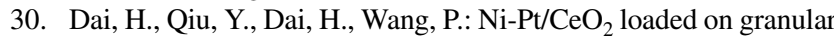
activated carbon : an efficient monolithic catalyst for controlled hydrogen generation from hydrous hydrazine. ACS Sustain. Chem. Eng. 6(8), 9876-9882 (2018)

31. Zhong, Y.J., Bin, D.H., Zhu, M., Wang, P.: Catalytic decomposition of hydrous hydrazine over $\mathrm{Ni}-\mathrm{Pt} / \mathrm{La}_{2} \mathrm{O}_{3}$ catalyst: a highperformance hydrogen storage system. Int. J. Hydrog. Energy 41, 11042-11049 (2016)

Publisher's Note Springer Nature remains neutral with regard to jurisdictional claims in published maps and institutional affiliations. 